\title{
バルビツル酸誘導體に關する研究（第五報） 4-イミノ-5-メチルチオバルビツル酸の銅鹽に就て
}

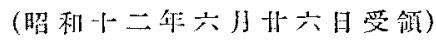

\begin{abstract}
速川武
\end{abstract}

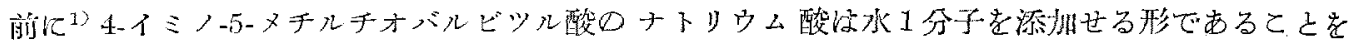

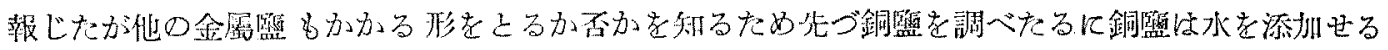

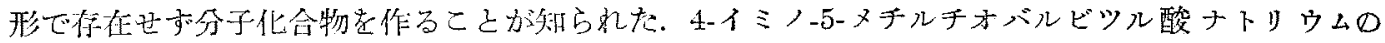

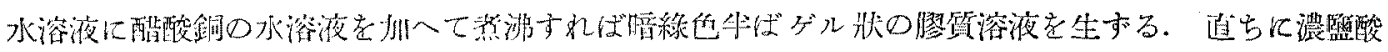

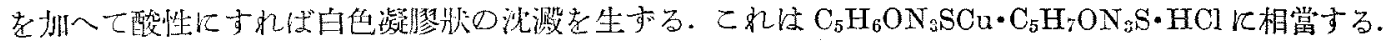

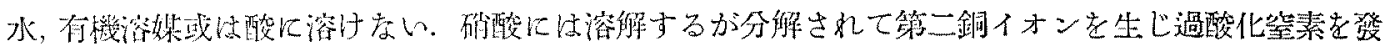

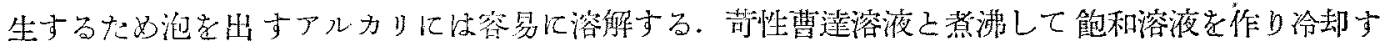

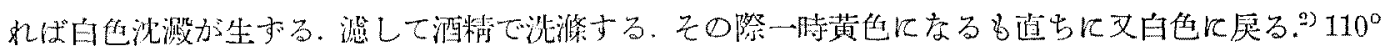

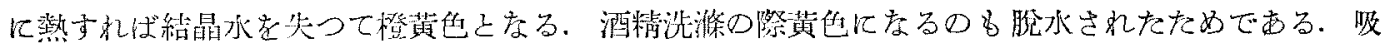

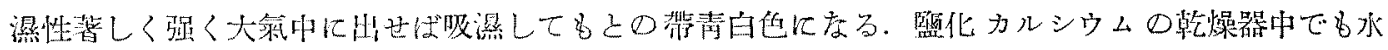

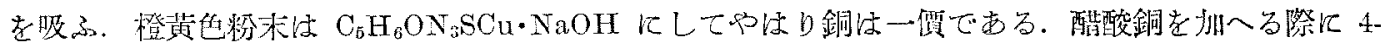

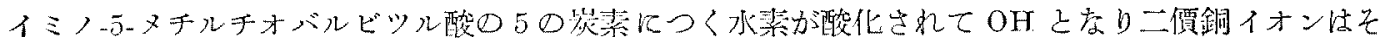

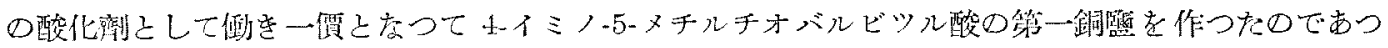

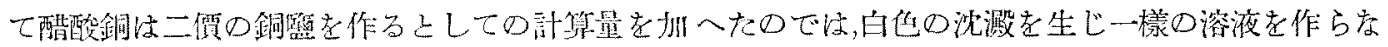

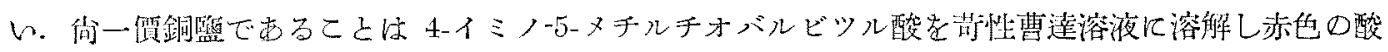

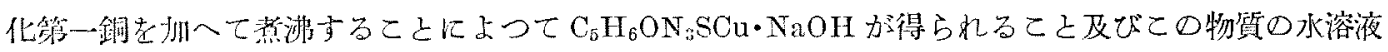

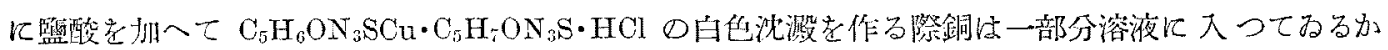

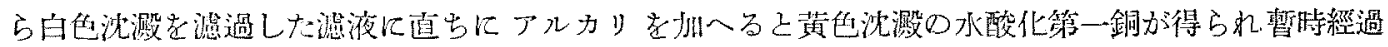

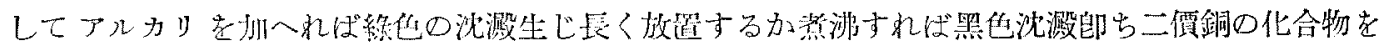
生亦るここによつて子秘好られる。

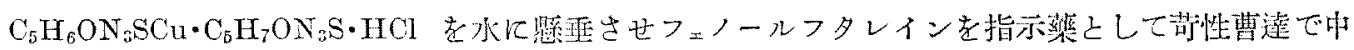

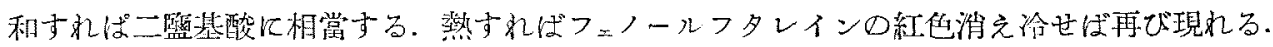

$$
\mathrm{C}_{5} \mathrm{H}_{6} \mathrm{ON}_{3} \mathrm{SCu} \cdot \mathrm{C}_{6} \mathrm{H}_{7} \mathrm{ON} 3 \cdot \mathrm{ICl}+2 \mathrm{NaOH}=\mathrm{C}_{5} \mathrm{H}_{6} \mathrm{ON}_{3} \mathrm{SCu}+\mathrm{C}_{5} \mathrm{H}_{3} \mathrm{O}_{2} \mathrm{~N}_{3} \mathrm{SNa}+\mathrm{NaCl}+\mathrm{H}_{2} \mathrm{O}
$$

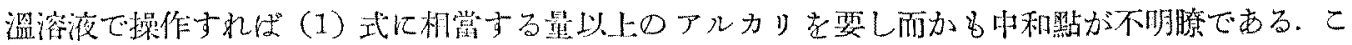
○現象○說明は後述する。

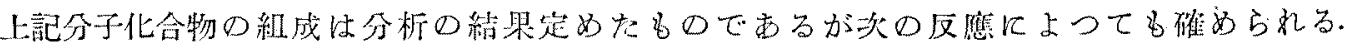

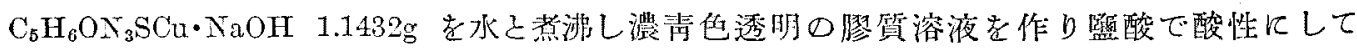

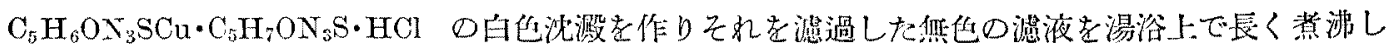

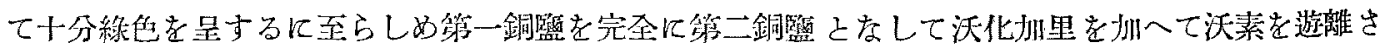

1) 本誌, $56(1935), 938$.

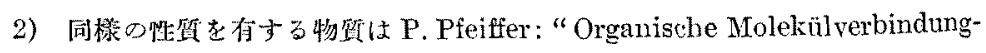
en," 2. Aufl, 74. に歹記载されてるる。 


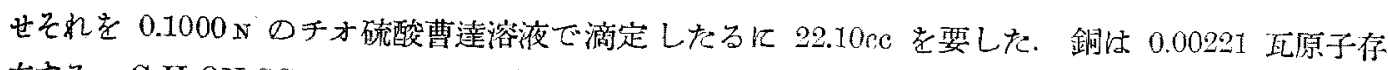

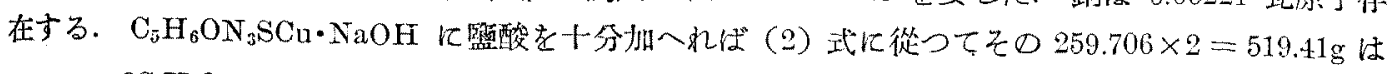
$2 \mathrm{C}_{5} \mathrm{H}_{6} \mathrm{ON}_{3} \mathrm{SCu} \cdot \mathrm{NaOH}+4 \mathrm{HCl}=\mathrm{C}_{5} \mathrm{H}_{6} \mathrm{ON}_{3} \mathrm{SCu} \cdot \mathrm{C}_{5} \mathrm{H}_{7} \mathrm{ON}_{3} \cdot \mathrm{HCl}+2 \mathrm{NaCl}+2 \mathrm{H}_{2} \mathrm{O}+\mathrm{CuCl} \cdot$

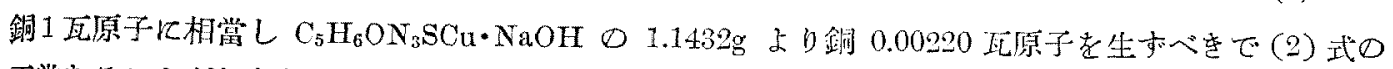
正賞なるここが知られる.

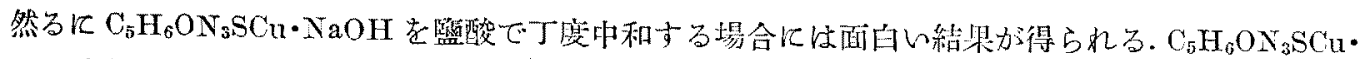
$\mathrm{NaOH}$ (分子量 259.706)の $0.1276 \mathrm{~g}$ をメチルオレンヂを指示藥しして $0.1000 \mathrm{~N}$ の監酸で滴定すれ

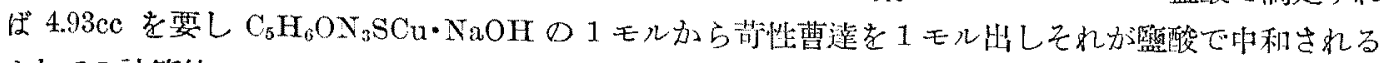

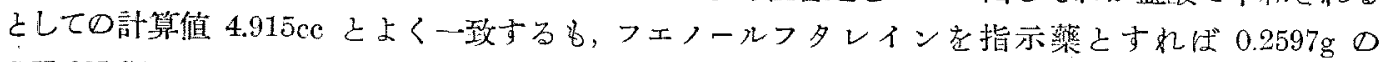

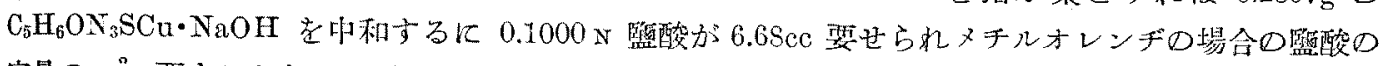
容量の产要するとしての計算值 $6.67 \mathrm{cc}$ とよく一致する. 從つてこの中和枚次の反應による.

$$
\begin{aligned}
& 2 \mathrm{C}_{5} \mathrm{H}_{6} \mathrm{ON}_{3} \mathrm{SCu} \cdot \mathrm{NaOH}+2 \mathrm{HCl}=2 \mathrm{C}_{5} \mathrm{H}_{6} \mathrm{ON}_{3} \mathrm{SCu}+2 \mathrm{NaCl}+2 \mathrm{H}_{2} \mathrm{O} \cdots \cdots \cdots \cdots \cdots(3 \mathrm{a}) \\
& 2 \mathrm{C}_{5} \mathrm{H}_{6} \mathrm{ON}_{3} \mathrm{SCu}+\mathrm{H}_{2} \mathrm{O}=\mathrm{C}_{\overline{0}} \mathrm{H}_{6} \mathrm{ON}_{3} \mathrm{SH}+\mathrm{C}_{5} \mathrm{H}_{6} \mathrm{ON}_{3} \mathrm{SCl} \cdot \mathrm{CuOH} \quad \cdots \cdots \cdots \cdots \cdots \cdots(3 \mathrm{~b}) \\
& \mathrm{C}_{5} \mathrm{H}_{6} \mathrm{ON}_{3} \mathrm{SCu} \cdot \mathrm{NaOH}+\mathrm{C}_{6} \mathrm{H}_{6} \mathrm{ON}_{3} \mathrm{SH}=\mathrm{C}_{5} \mathrm{H}_{6} \mathrm{ON}_{3} \mathrm{SCu}+\mathrm{C}_{6} \mathrm{H}_{8} \mathrm{O}_{2} \mathrm{~N}_{3} \mathrm{SCu} \\
& \mathrm{C}_{5} \mathrm{H}_{5} \mathrm{ON}_{3} \mathrm{SCu} \cdot \mathrm{CnOH}+\mathrm{C}_{5} \mathrm{H}_{6} \mathrm{ON}_{3} \mathrm{SCu}=\left(\mathrm{C}_{5} \mathrm{H}_{6} \mathrm{ON}_{3} \mathrm{SCu}\right)_{2} \mathrm{CuOH}
\end{aligned}
$$

䌭れぱ

$$
3 \mathrm{C}_{5} \mathrm{H}_{6} \mathrm{ON}_{3} \mathrm{SCu} \cdot \mathrm{NaOH}+2 \mathrm{HCl}=\left(\mathrm{C}_{6} \mathrm{H}_{6} \mathrm{ON}_{3} \mathrm{SCu}\right)_{2} \mathrm{CuOH}+\mathrm{C}_{5} \mathrm{H}_{3} \mathrm{O}_{2} \mathrm{NSNa}+2 \mathrm{NaCl}+\mathrm{H}_{2} \mathrm{O} \cdots
$$

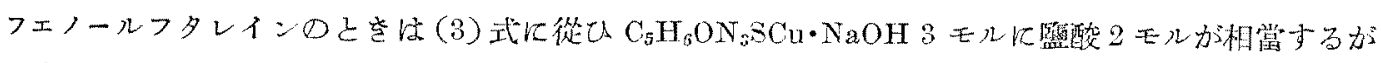

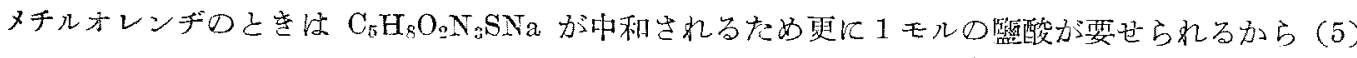

$$
\mathrm{C}_{5} \mathrm{H}_{5} \mathrm{O}_{2} \mathrm{~N}_{3} \mathrm{SNa}+\mathrm{HCl}=\mathrm{C}_{5} \mathrm{H}_{7} \mathrm{ON}_{3} \mathrm{~S}+\mathrm{NaCl}+\mathrm{H}_{2} \mathrm{O}
$$

(3) と (4) 上り $3 \mathrm{C}_{6} \mathrm{H}_{6} \mathrm{ON}_{3} \mathrm{SCu} \cdot \mathrm{NaOH}+3 \mathrm{HCl}=\left(\mathrm{C}_{5} \mathrm{H}_{6} \mathrm{ON}_{3} \mathrm{SCu}\right)_{2} \mathrm{CuOH}+\mathrm{C}_{5} \mathrm{H}_{7} \mathrm{ON} \mathrm{N}_{3} \mathrm{~S}+3 \mathrm{NaCl}+2 \mathrm{H}_{2} \mathrm{O} \cdots$ (5) 式に從し $\mathrm{C}_{5} \mathrm{H}_{6} \mathrm{ON}_{5} \mathrm{SCu} \cdot \mathrm{NaOH}$ 己祭酸のモル数の比は1:1である. 又更に多量の盤酸を都へれば $\left(\mathrm{C}_{5} \mathrm{H}_{6} \mathrm{ON}_{3} \mathrm{SCu}\right)_{2} \mathrm{CuOH}$ が (6) 式從つて分解されるのであつて (5) 式と（6）式と組分せると(2)

$2 \mathrm{C}_{5} \mathrm{H}_{7} \mathrm{ON}_{3} \mathrm{~S}+2\left(\mathrm{C}_{6} \mathrm{H}_{6} \mathrm{ON}_{3} \mathrm{SCu}\right)_{2} \mathrm{CuOH}+6 \mathrm{HCl}=3 \mathrm{C}_{\bar{a}} \mathrm{H}_{6} \mathrm{ON}_{3} \mathrm{SCu} \cdot \mathrm{C}_{5} \mathrm{H}_{7} \mathrm{ON} \mathrm{N}_{3} \mathrm{~S} \cdot \mathrm{HCl}+3 \mathrm{CuCl}+2 \mathrm{H}_{2} \mathrm{O}$

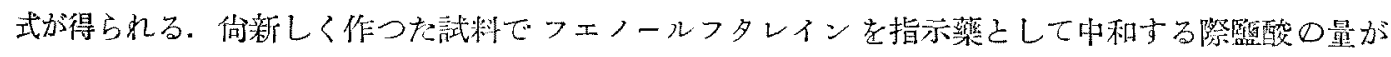

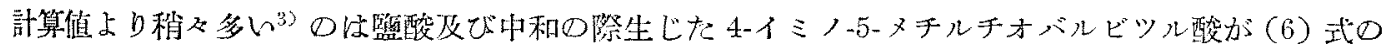
反應を起して多少消費导れるによる。

又面白いことには中和の終近くになるこ一旦フェノールフタレインの紅出消え溶液は淡青線せを

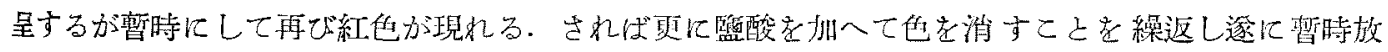

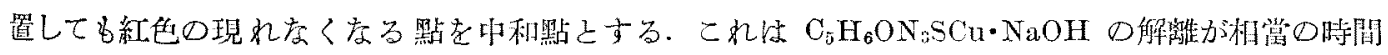

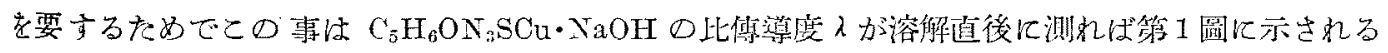

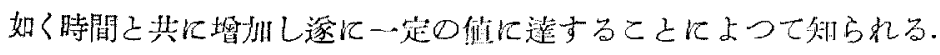

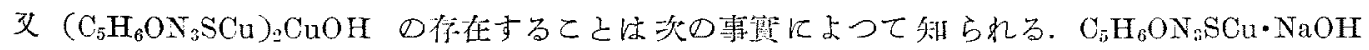
$0.2597 \mathrm{~g}$ を水に溶玑し サーイミノ-5ーメチルチオバルビツル酸を $0.1571 \mathrm{~g}$

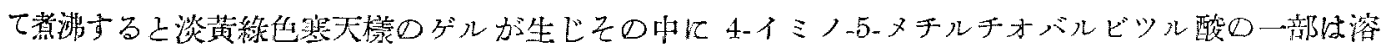

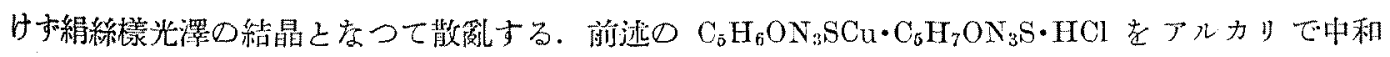
する際熱するとフェノールフタレインの紅出が消えるのも $\mathrm{C}_{5} \mathrm{H}_{6} \mathrm{ON}_{3} \mathrm{SCu}$ が分解して4-イミノー5-メ

3) 賽驗の部參照. 


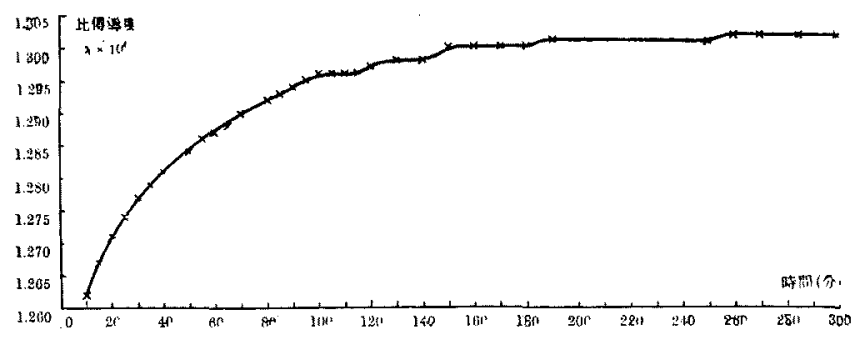

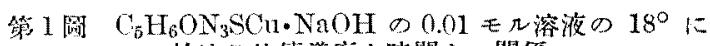
於けを比傅渞度と時閒との關係
チルチオバルビツル酸主崸しそれが アルカリをとるによる.4ーイミノ-5メチルチオバルビッル酸と酸化第一 銅の1モル妴の割合の混合物に水を

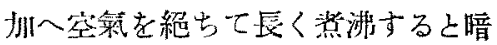

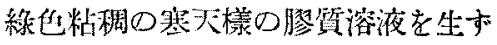
る. 米作朋の酸や酸优第一銅を浪し

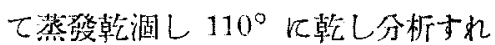

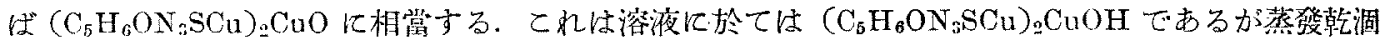

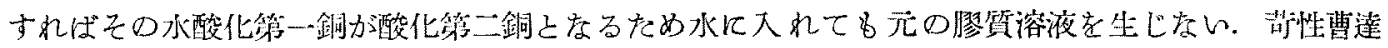

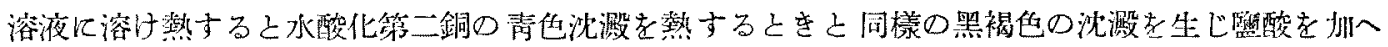

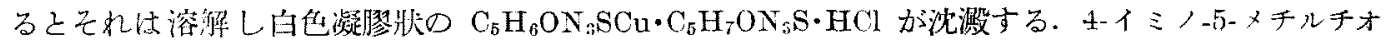

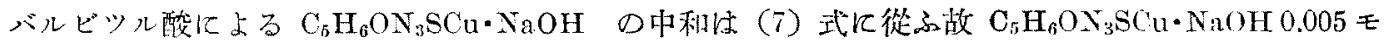

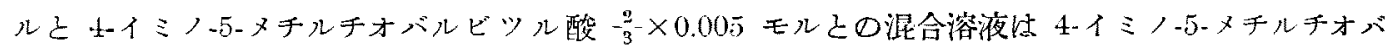

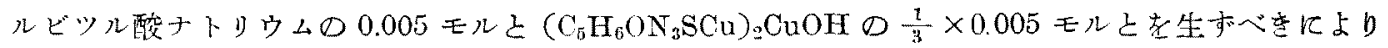
4-イミノ-5-メチルチオバルビツル酸ナトリウムの 0.005 モル溶液と比傳導度が同じに李る䉥で $18^{\circ}$

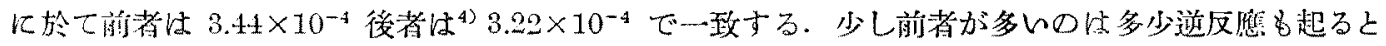
思机れる。

$3 \mathrm{C}_{6} \mathrm{H}_{6} \mathrm{ON}_{3} \mathrm{SCu} \cdot \mathrm{Cu} \cdot \mathrm{NaOH}+2 \mathrm{C}_{5} \mathrm{H}_{7} \mathrm{ON}_{3} \mathrm{~S}+\mathrm{H}_{2} \mathrm{O}=3 \mathrm{C}_{6} \mathrm{H}_{3} \mathrm{O}_{2} \mathrm{~N}_{3} \mathrm{SNa}+\left(\mathrm{C}_{6} \mathrm{H}_{6} \mathrm{ON}_{3} \mathrm{SCn}\right)_{2} \mathrm{CnOH}$

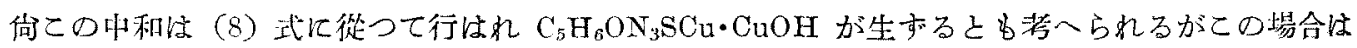

$$
\begin{aligned}
& 2 \mathrm{C}_{5} \mathrm{H}_{6} \mathrm{ON}_{3} \mathrm{SCn} \cdot \mathrm{NaOH}+2 \mathrm{C}_{6} \mathrm{H}_{7} \mathrm{ON}_{3} \mathrm{~S}=2 \mathrm{C}_{5} \mathrm{H}_{6} \mathrm{ON}_{3} \mathrm{SCu}+2 \mathrm{C}_{5} \mathrm{H}_{8} \mathrm{O}_{2} \mathrm{~N}_{3} \mathrm{SNa} \ldots \ldots \ldots \ldots \\
& 2 \mathrm{C}_{6} \mathrm{H}_{6} \mathrm{ON}_{3} \mathrm{SCu}+\mathrm{H}_{2} \mathrm{O}=\mathrm{C}_{6} \mathrm{H}_{7} \mathrm{ON}_{3} \mathrm{~S}+\mathrm{C}_{6} \mathrm{H}_{6} \mathrm{ON}_{3} \mathrm{SCn} \cdot \mathrm{CuOH} \ldots \ldots \ldots \ldots \ldots \ldots \ldots \ldots
\end{aligned}
$$

喵ち $2 \mathrm{C}_{5} \mathrm{H}_{6} \mathrm{ON} \mathrm{N}_{3} \mathrm{SCu} \cdot \mathrm{NaOH}+\mathrm{C}_{\overline{0}} \mathrm{H}_{7} \mathrm{ON}_{3} \mathrm{~S}+\mathrm{H}_{2} \mathrm{O}=2 \mathrm{C}_{5} \mathrm{H}_{8} \mathrm{O}_{2} \mathrm{~N}_{3} \mathrm{SNa}+\mathrm{C}_{5} \mathrm{H}_{6} \mathrm{ON}_{3} \mathrm{SCu} \cdot \mathrm{CnOH} \cdot$

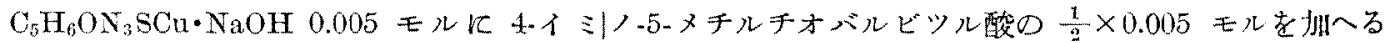

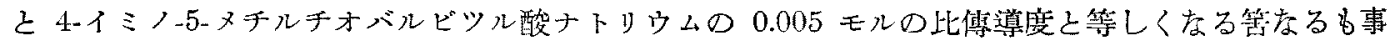

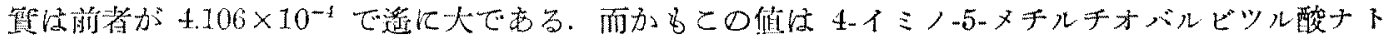
リウ $ム \oslash \frac{3}{4} \times 0.005 モ ル と \mathrm{C}_{5} \mathrm{H}_{6} \mathrm{ON}_{3} \mathrm{SCu} \cdot \mathrm{NaOH} \oslash \frac{1}{4} \times 0.005$ モ几の混合溶液の比傅導度 $4.137 \times 10^{-4}$

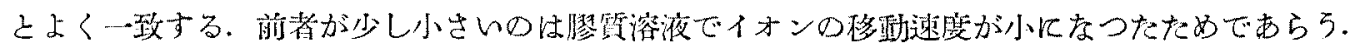

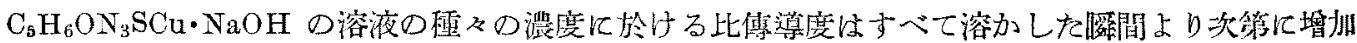

第表

$\mathrm{C}_{5} \mathrm{H}_{6} \mathrm{ON}_{3} \mathrm{SCu} \cdot \mathrm{NaOH}$ 水溶液の $18^{\circ}$ に於ける比傅導度及び解離度

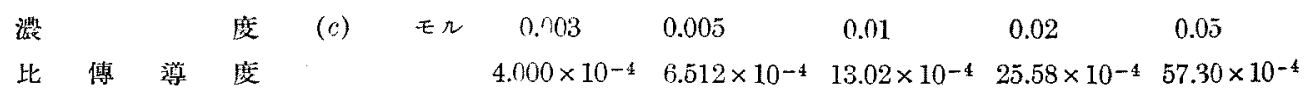

4) 本誋, 56(1935), 937 . 


\begin{tabular}{|c|c|c|c|c|c|c|c|}
\hline 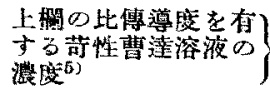 & $\left(c^{\prime}\right)$ & $\mathrm{N}$ & 0.00195 & 0.0032 & 0.0064 & $0.0128 \overline{-}$ & 0.0295 \\
\hline $\begin{array}{l}\text { I 及び I によると } \\
\text { しての解脽胶 }\end{array}$ & $\left(\frac{c^{\prime}}{c}\right)$ & & 0.65 & 0.64 & 0.64 & 0.64 & 0.59 \\
\hline 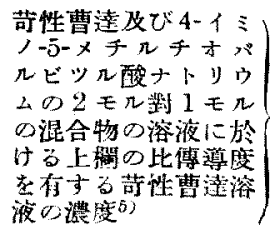 & $\left(c^{\prime \prime}\right)$ & $\mathrm{x}$ & 0.00157 & 0.00265 & . $\quad 0.005 \tilde{0} 0$ & 0.01105 & 0.0252 \\
\hline $\operatorname{III~}_{\text {燔離度 }}$ & $\left(\begin{array}{c}c^{\prime \prime} \\
\frac{3}{3} c\end{array}\right)$ & & 0.79 & 0.80 & 0.83 & 0.83 & 0.76 \\
\hline
\end{tabular}

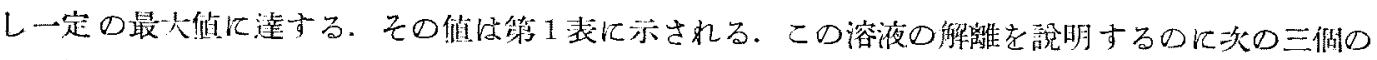
式が若へられる。

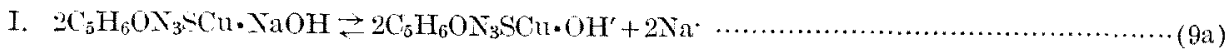

$\mathrm{C}_{5} \mathrm{H}_{6} \mathrm{ON}_{3} \mathrm{SCu} \cdot \mathrm{NaOH}+\mathrm{C}_{6} \mathrm{H}_{6} \mathrm{ON}_{3} \mathrm{SCu} \cdot \mathrm{OH}^{\prime} \rightleftarrows\left(\mathrm{C}_{6} \mathrm{H}_{6} \mathrm{ON}_{3} \mathrm{SCu}\right)_{2} \mathrm{NaOH}+\mathrm{OH}^{\prime}$

即古 $3 \mathrm{C}_{5} \mathrm{H}_{6} \mathrm{ON}_{3} \mathrm{SCu} \cdot \mathrm{NaOH} \rightleftarrows\left(\mathrm{C}_{5} \mathrm{H}_{6} \mathrm{ON}_{3} \mathrm{SCl}_{2}\right)_{2} \mathrm{NaOH}+\mathrm{C}_{6} \mathrm{H}_{6} \mathrm{ON}_{3} \mathrm{SCn} \cdot \mathrm{OH}^{\prime}+\mathrm{OH}^{\prime}+2 \mathrm{Na}$.

II. $\mathrm{C}_{5} \mathrm{H}_{5} \mathrm{ON}+\mathrm{Cu} \cdot \mathrm{\textrm {NaOH }} \underset{\mathrm{C}}{\mathrm{C}} \mathrm{H}_{6} \mathrm{ON}_{3} \mathrm{SCn}+\mathrm{Na}$. $+\mathrm{OH}^{\prime}$

III. $3 \mathrm{C}_{5} \mathrm{H}_{6} 0 \mathrm{X}_{3} \mathrm{SCu} \cdot \mathrm{XaOH} \rightleftarrows 3 \mathrm{C}_{6} \mathrm{H}_{6} \mathrm{ON}_{3} \mathrm{SCn}+3 \mathrm{Xa}^{2}+30 \mathrm{H}^{\prime}$

$3 \mathrm{C}_{5} \mathrm{H}_{6} \mathrm{ON}_{3} \mathrm{SCu}+\mathrm{H}_{2} \mathrm{O}+\mathrm{OH}^{\prime} \rightleftarrows\left(\mathrm{C}_{5} \mathrm{H}_{6} \mathrm{ON}_{3} \mathrm{SCu}\right)_{2} \mathrm{CuOH}+\mathrm{C}_{5} \mathrm{H}_{5} \mathrm{O}_{2} \mathrm{~N}_{3} \mathrm{~S}^{\prime}$

跑方 $3 \mathrm{C}_{5} \mathrm{H}_{6} \mathrm{OS} \mathrm{CCu} \cdot \mathrm{XaOH}+\mathrm{H}_{2} \mathrm{O} \rightarrow\left(\mathrm{C}_{5} \mathrm{H}_{6} \mathrm{ON}_{3} \mathrm{SCu}\right)_{2} \mathrm{CuOH}+3 \mathrm{Na}^{2}+2 \mathrm{OH}^{\prime}+\mathrm{C}_{5} \mathrm{H}_{8} \mathrm{O}_{2} \mathrm{~N}_{3} \mathrm{~S}^{2}$

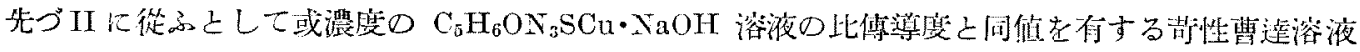

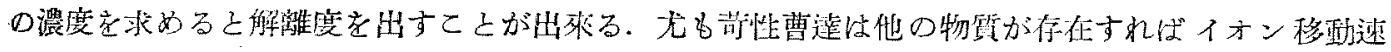

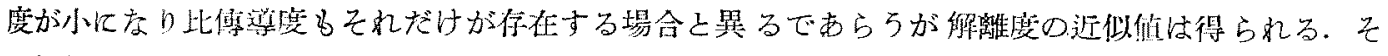

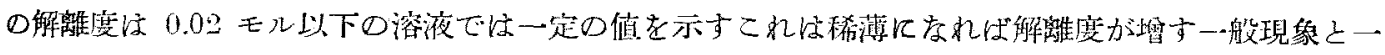

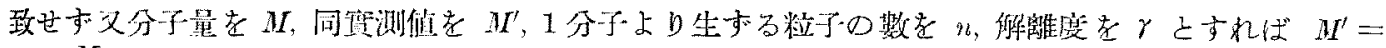

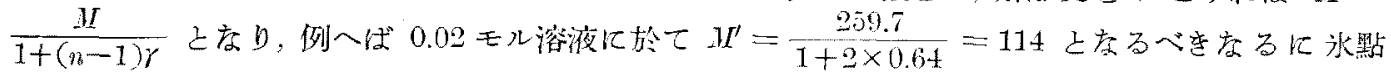

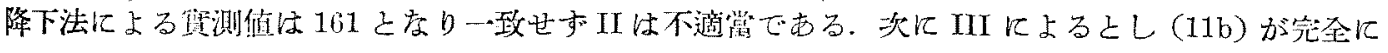

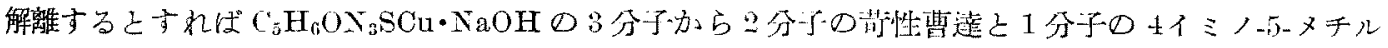

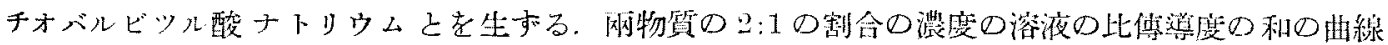

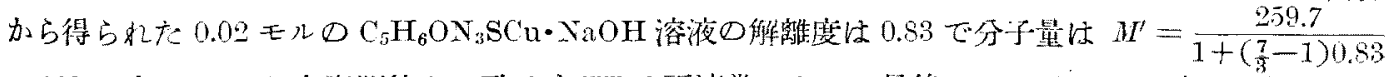

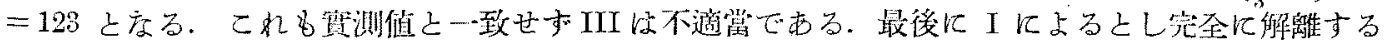

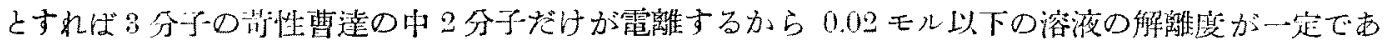

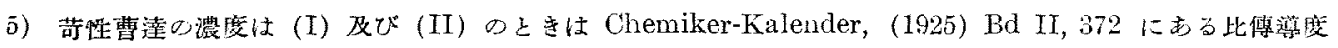

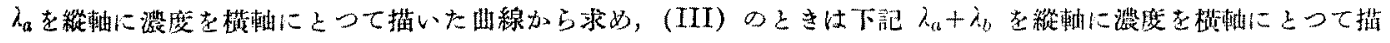

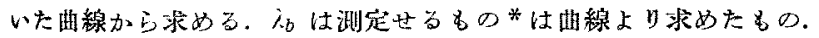
遭度
(x)
$\begin{array}{llll}0.001 & 0.002 & 0.00\end{array}$
$\begin{array}{lllllll}0.005 & 0.01 & 0.02 & 0.03 & 0.04 & 0.05 & 0.1\end{array}$
此傅薄度
$\left(\lambda_{t}\right) \times 10^{4}$
$2.08 \quad 4.12$
$8.22 *$
$\begin{array}{lllllll}10.15 & 20.0 & 39.4 & 58.2 & 77.0 * & 95.0 & 183\end{array}$
N/2 の濃度の4-1ミノー5-メチルチォバルビッれ酸

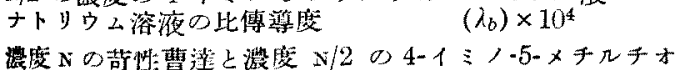
$1.3 \overline{0}$
$\begin{array}{lll}3.22 & 6.38 & 12.1\end{array}$
29.0

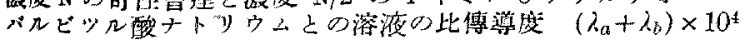
9.57
$23.2 \quad 45.8$
89.1
21.2 


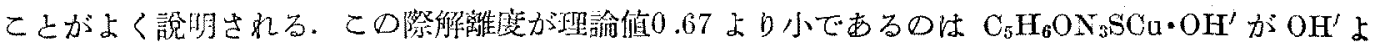

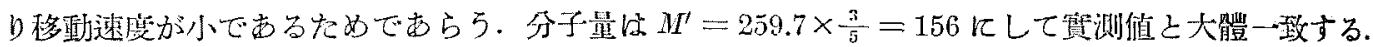

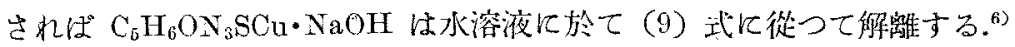

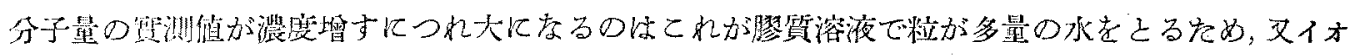

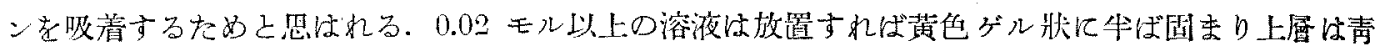

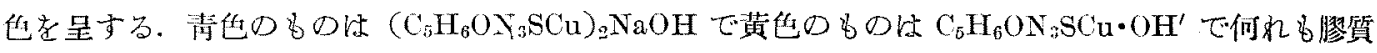

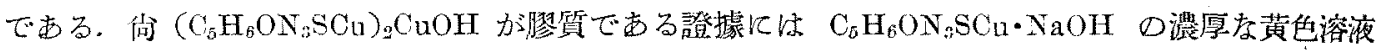

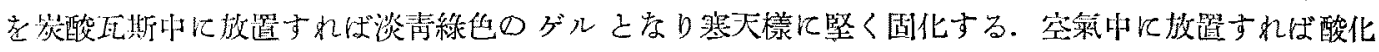

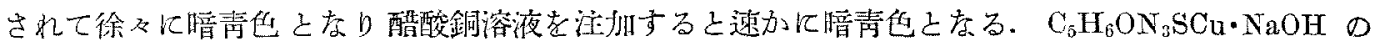

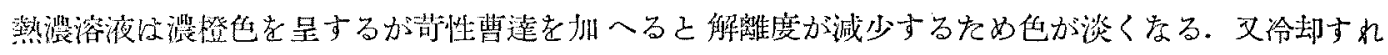

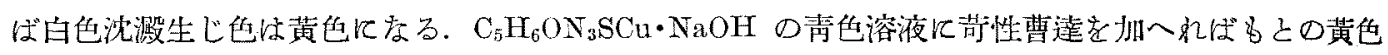

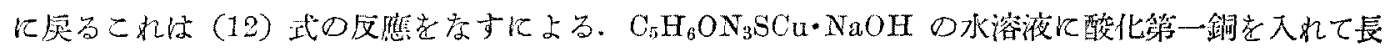

$$
\left(\mathrm{C}_{5} \mathrm{H}_{6} \mathrm{ON}_{3} \mathrm{SCu}\right)_{2} \mathrm{NaOH}+\mathrm{NaOH}=2 \mathrm{C}_{6} \mathrm{H}_{6} \mathrm{ON}_{3} \mathrm{SCu} \cdot \mathrm{NaOH}
$$

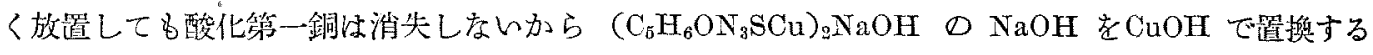

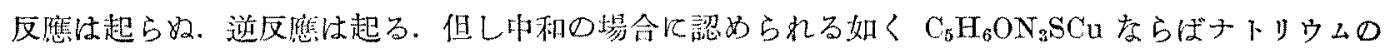
代りに銅岩入れ得るのである。

\section{實 驗 の 部}

$\mathrm{C}_{5} \mathrm{H}_{6} \mathrm{ON}_{3} \mathrm{SCu} \cdot \mathrm{NaOH}$ の製法 4-イミノー5-メチルチオバルビツル酸 $1.0 \mathrm{~g}$ K酸化第一銅 $0.45 \mathrm{~g}$ 加

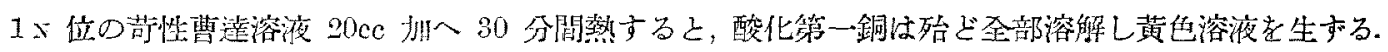

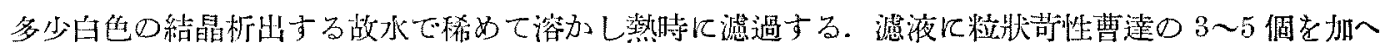

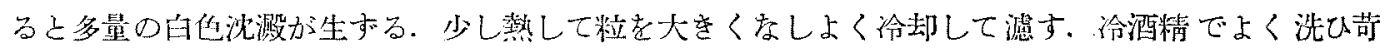

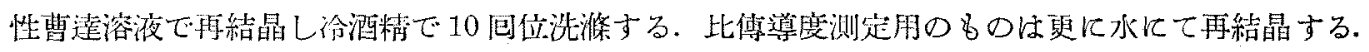

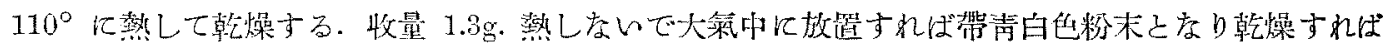

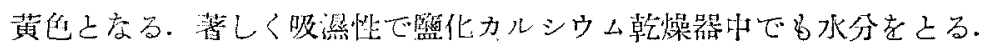

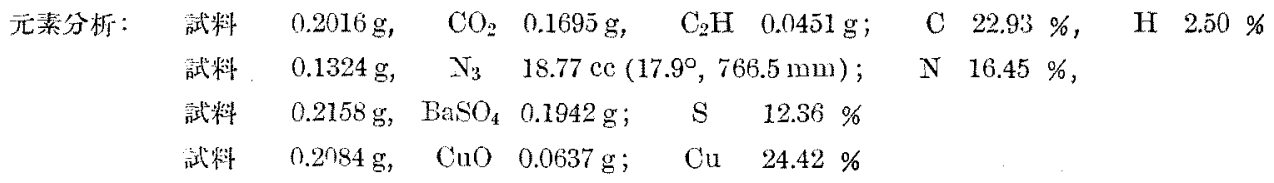
$\mathrm{C}_{5} \mathrm{H}_{6} 0 \mathrm{~N}_{3} \mathrm{SCn}, \mathrm{NaOH}$ 乙しての計算值 C $23.10 \%$ H $2.72 \%$ X $16.18 \%$
S $12.35 \%$
Cu $24.48 \%$

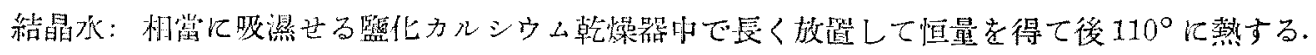
試 粘
$0.3046 \mathrm{~g}$,
減 量 $0.0200 \mathrm{~g}$;
$\mathrm{H}_{2} \mathrm{O} \quad 6.57 \%$
$\mathrm{C}_{5} \mathrm{H}_{6} \mathrm{ON}_{3} \mathrm{SCu} \cdot \mathrm{NaOH} \cdot \mathrm{H}_{2} \mathrm{O}$ としての諎算値
$\mathrm{H}_{2} \mathrm{O} \quad 6.49 \%$

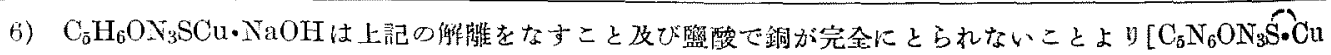

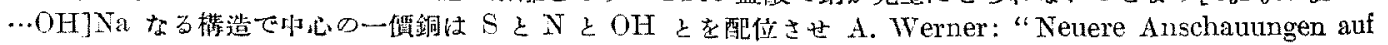

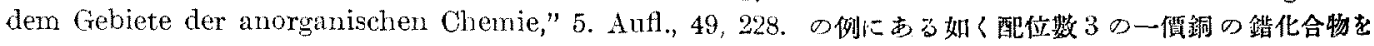
なすものであらら 


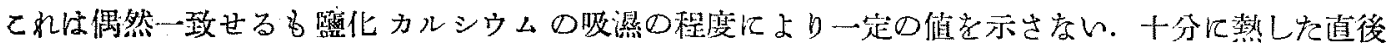

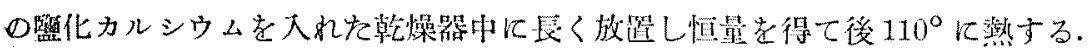

$\begin{array}{cccc}\text { 試 料 } 2.1382 \mathrm{~g} \cdot \quad \text { 娍 量 } 0.0733 \mathrm{~g} ; & \mathrm{H}_{2} \mathrm{O} & 3.43 \% \\ & \mathrm{C}_{5} \mathrm{H}_{6} \mathrm{ON}_{3} \mathrm{SCu} \cdot \mathrm{NaOH} \cdot{ }_{2}^{1} \mathrm{H}_{2} \mathrm{O} \text { としての暗算値 } & \mathrm{H}_{2} \mathrm{O} & 3.35 \%\end{array}$

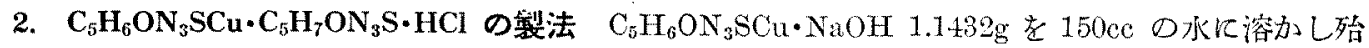

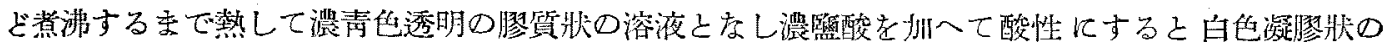

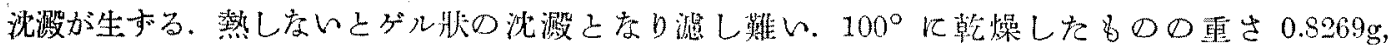

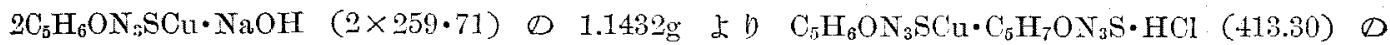

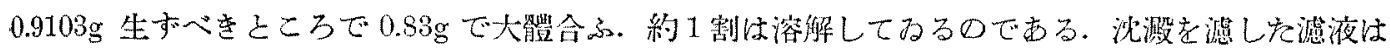

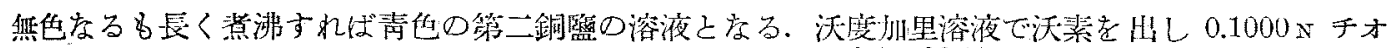

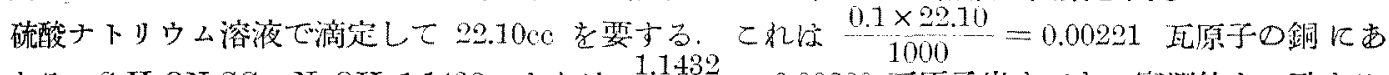

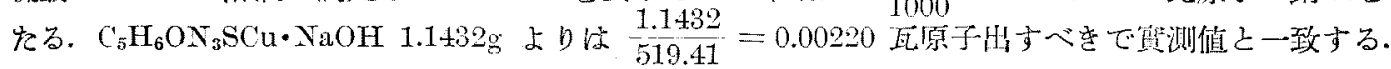

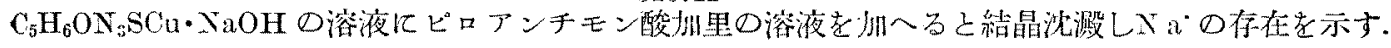

$\begin{array}{llllll}\text { 元素分析： } & \text { 試 料 } & 0.1331 \mathrm{~g}, & \mathrm{~N}_{2} 22.95 \mathrm{ce}\left(14.5^{\circ}, 774.9 \mathrm{~mm}\right) ; \\ & \text { 試 料 } & 0.2038 \mathrm{~g}, & \mathrm{AgCl} 0.0706 \mathrm{~g} ; & \mathrm{Cl} \quad 8.57 \% \\ & \text { 試 料 } & 0.2073 \mathrm{~g}, & \mathrm{BaSO}_{4} 0.2368 \mathrm{~g} ; & \mathrm{S} 15.68 \% \\ & \text { 試 料 } & 0.2008 \mathrm{~g}, & \mathrm{CuO} 0.0393 \mathrm{~g} ; & \mathrm{Cu} 15.64 \%\end{array}$

$\mathrm{C}_{5} \mathrm{H}_{6} \mathrm{ON}_{3} \mathrm{SCu} \cdot \mathrm{C}_{5} \mathrm{H}_{7} \mathrm{ON} \mathrm{S} \cdot \mathrm{HCl}$ としての訫算值 $\mathrm{N} \quad 20.54 \% ， \quad \mathrm{Cl} \quad 8.58 \% ， \quad \mathrm{~S} \quad 15.51 \% \quad \mathrm{Cu} 15.38 \%$

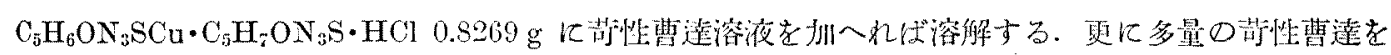

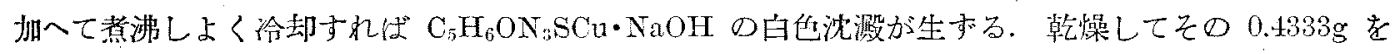

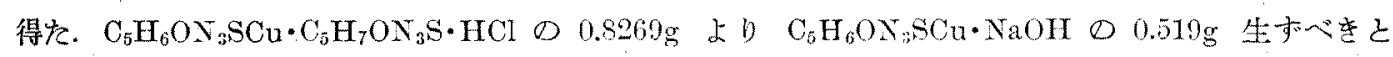
ころ $0.43 \mathrm{~g}$ で大體合ふ。的1割は溶液となつてみる。

3. $\mathrm{C}_{5} \mathrm{H}_{6} \mathrm{ON}_{3} \mathrm{SCu} \cdot \mathrm{NaOH}$ 及び $\mathrm{C}_{53} \mathrm{H}_{6} \mathrm{ON}_{3} \mathrm{SCu} \cdot \mathrm{C}_{5} \mathrm{H}_{7} \mathrm{ON} \mathrm{N}_{3} \mathrm{~S} \cdot \mathrm{HCl}$ の滴定 a) $\mathrm{C}_{5} \mathrm{H}_{6} \mathrm{ON}_{5} \mathrm{SCu} \cdot \mathrm{XaOH} \oslash$

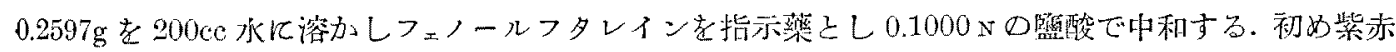
色を呈し中和されると淡綠巴となるが整時にして紅色が再び現れ，完全に中和されると淡綠出が變色

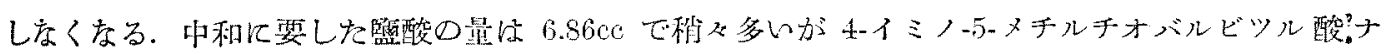

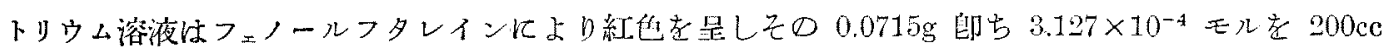
の水に溶かしフェノールフタレインと溶液に青やを呈させるためのブロモチモールブルーとを抓てて

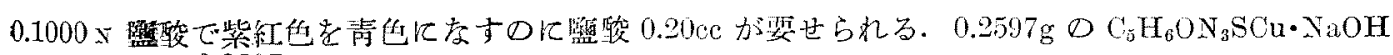
から生和る $\frac{0.2597}{259.7 \times 3}=3.333 \times 10^{-1}$ モルの4ーイミノー5-メチルチオバルビッル酸ナトリウムには

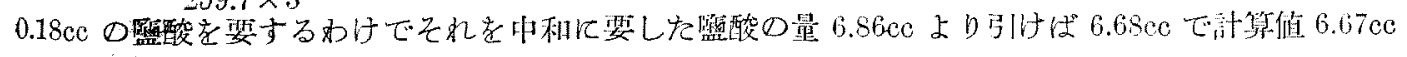
と一致する.

\begin{tabular}{|c|c|c|c|c|}
\hline \multirow{2}{*}{ 試 料 } & \multirow{2}{*}{ 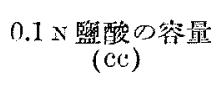 } & \multirow{2}{*}{ 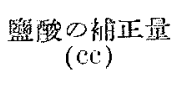 } & \multicolumn{2}{|c|}{ 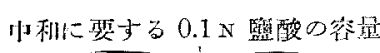 } \\
\hline & & & 活澌值 (ce) & 計算值 $(\mathrm{ce})$ \\
\hline 0.2597 & 6.86 & 0.18 & 6.68 & 0.657 \\
\hline 0.2020 & 5.38 & 0.14 & 5.24 & 5.19 \\
\hline
\end{tabular}

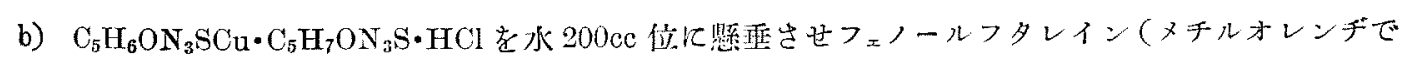




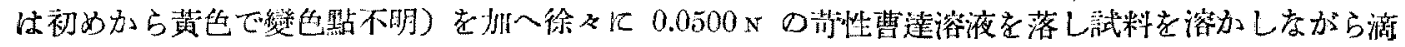
定する.

試料 $0.2067 \mathrm{~g}$, 苛性曹涚溶液 $20.39 \mathrm{ce}$ ，会部算储 $20.00 \mathrm{cc}$.

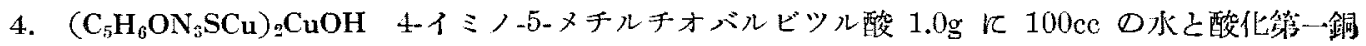

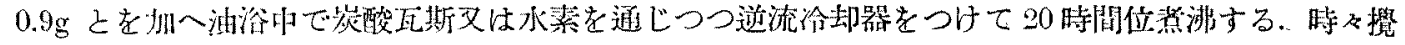

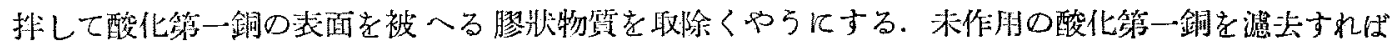

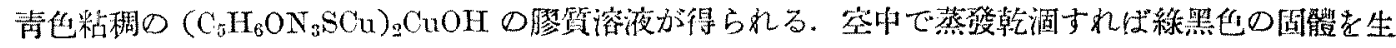

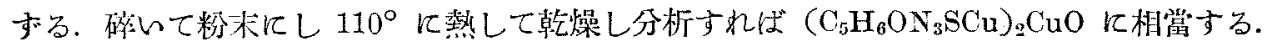

$$
\begin{aligned}
& \text { 元素分析： 試料 } \quad 0.1987 \mathrm{~g}, \quad \mathrm{~N}_{2} 27.60 \mathrm{cc}\left(17.5^{\circ}, 763.5 \mathrm{~mm}\right) ; \quad \mathrm{N} 16.09 \% \\
& \text { 試料 } 0.2014 \mathrm{~g}, \quad \mathrm{CuO} \quad 0.0921 \mathrm{~g}, \quad \mathrm{BaSO}_{4} \quad 0.1904 . \mathrm{g} ; \quad \mathrm{Cu} 36.53 \%, \quad \mathrm{~S} \quad 12.98 \% \\
& \left(\mathrm{C}_{5} \mathrm{H}_{6} \mathrm{ON}_{3} \mathrm{SCn}\right)_{2} \mathrm{CnO} \text { 己しての計算值 } \quad \mathrm{N} 16.20 \% \mathrm{Cu} \quad 36.75 \% ， \quad \mathrm{~T} \quad 12.36 \%
\end{aligned}
$$

一旦乾燥したものは水に溶け和荷性曹迋溶液に溶けるが通ちに黑褐色の沈澱が析出しそれに監酸を

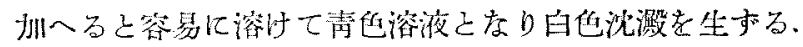

5. $\mathrm{C}_{-} \mathrm{H}_{6} \mathrm{ON} \mathrm{ONCu}_{3} \mathrm{SCaOH}$ 水溶液の $18^{\circ}$ に於ける比傳導度 a) $\mathrm{C}_{5} \mathrm{H}_{6} \mathrm{ON}_{3} \mathrm{SCu} \cdot \mathrm{NaOH} O(\mathrm{I}) 0.0779 \mathrm{~g}$. (II) $0.1299 \mathrm{~g}$ 老及 $100 \mathrm{cc}$ ○水溶液となし, (III) 同じく $0.1299 \mathrm{~g}$ を $50 \mathrm{cc}$ の水溶液となし. (IV)

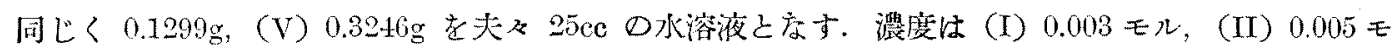
ル，(III） 0.01 モル，(IV） $0.02 モ ル ，(V) ~ 0.05$ モルである. 抵抗容量 0.2476 の容器に溶液を入れ

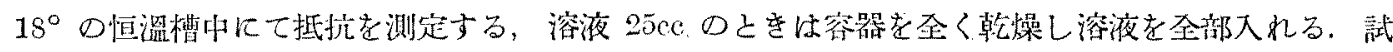
料は乾燥器に長く放置せるものは岑酸瓦斯を吸つて表面に膠質物質が出來てるるため溶解速度小で

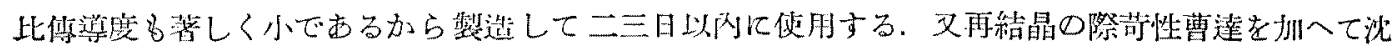

\begin{tabular}{|c|c|c|c|c|c|c|}
\hline \multirow[b]{2}{*}{ 時間(分) } & \multicolumn{2}{|c|}{ I $(0.003 \varepsilon \pi)$} & \multicolumn{2}{|c|}{ II $(0.005 モ \pi)$} & \multicolumn{2}{|c|}{$\operatorname{III}(0.01$ モル) } \\
\hline & 抵 抗 & 比傅薄度 $\times 10^{1}$ & 抵 抗 & 比傅溥度 $\times 10^{4}$ & 扯 抗 & 比傅導度 $\times 10^{3}$ \\
\hline $\begin{array}{l}10 \\
15\end{array}$ & & & 385.6 & 6.421 & 196.2 & 1.262 \\
\hline 15 & 623.6 & 3.971 & 385.2 & 6.428 & 195.4 & 1.262 \\
\hline 20 & 623.3 & 3.972 & 384.4 & $6.44 \mathrm{I}$ & 194.8 & 1.271 \\
\hline 25 & 622.6 & 3.977 & 384.0 & 6.448 & 194.4 & 1.274 \\
\hline 30 & 622.3 & 3.979 & 383.6 & $6.45 \bar{~}$ & 193.9 & 1.277 \\
\hline 35 & 621.5 & 3.984 & 382.9 & 6.466 & 193.6 & 1.279 \\
\hline 40 & 621.4 & 3.985 & 382.7 & 6.470 & 193.3 & $1.28 \mathrm{I}$ \\
\hline $\begin{array}{l}45 \\
50\end{array}$ & $\begin{array}{l}621.0 \\
622.5\end{array}$ & $\begin{array}{l}3.987 \\
3.990\end{array}$ & 382.2 & 6.478 & 192.8 & 1.284 \\
\hline 55 & & & 381.9 & 6.483 & 192.6 & $\begin{array}{l}1.204 \\
1.286\end{array}$ \\
\hline 60 & 620.0 & 3.994 & 381.6 & 6.489 & 192.4 & 1.287 \\
\hline $\begin{array}{l}60 \\
70\end{array}$ & & & & & 192.2 & 1.288 \\
\hline 75 & 620.0 & 3.994 & $\begin{array}{l}381.4 \\
381.2\end{array}$ & $\begin{array}{l}6.492 \\
6.495\end{array}$ & 192.0 & 1.290 \\
\hline 80 & & & 581.0 & 6.499 & 191.7 & 1.212 \\
\hline 85 & 619.3 & 3.998 & 381.0 & 6.499 & 191.5 & 1.293 \\
\hline 90 & 619.0 & 4.000 & & & 191.4 & 1.294 \\
\hline 95 & 619.0 & 4.000 & 380.8 & 6.502 & 191.2 & 1.295 \\
\hline 100 & 619.0 & 4.000 & 380.8 & 6.502 & 191.1 & 1.296 \\
\hline 105 & 819.0 & 4.000 & 380.6 & 6.506 & 191.0 & 1.296 \\
\hline 110 & $615.7)$ & 4.000 & 380.6 & 6.506 & 191.0 & 1.296 \\
\hline 110 & & & 380.5 & 6.507 & 191.0 & 1.296 \\
\hline 120 & & & 380.4 & 6.509 & 190.9 & 1.297 \\
\hline
\end{tabular}

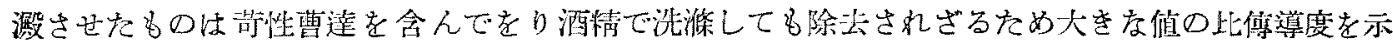
与. 


$\begin{array}{ll}380.3 & 6.511 \\ 380.3 & 6.511 \\ 380.2 & 6.512 \\ 380.2 & 6.512 \\ 380.2 & 6.512\end{array}$

\begin{tabular}{|c|c|c|c|c|}
\hline \multirow[b]{2}{*}{ 時間(時) } & \multicolumn{2}{|c|}{$I V(0.02 \leftleftarrows n)$} & \multicolumn{2}{|c|}{$Y(0.05$ E } \\
\hline & 抵抗 & 比佯導度 $\times 10^{3}$ & 抵抗 & 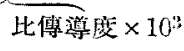 \\
\hline $\begin{array}{l}0.25 \\
0.5\end{array}$ & $\begin{array}{l}108.4 \\
107.1\end{array}$ & $\begin{array}{l}2.284 \\
2.312\end{array}$ & 52.34 & 4.731 \\
\hline 0.6 & & & 50.55 & 4.898 \\
\hline 1.0 & 105.2 & 2.354 & 49.16 & 5.037 \\
\hline 1.5 & 104.2 & 2.376 & 47.89 & 5.170 \\
\hline 2.0 & 103.6 & 2.390 & 46.58 & 5.316 \\
\hline 2.5 & 103.1 & 2.402 & 45.37 & $5.45^{2}$ \\
\hline 3.0 & 102.8 & 2.409 & 44.59 & 5.503 \\
\hline 3.5 & 102.6 & 2.413 & 44.14 & 5.609 \\
\hline 4.0 & & & 43.87 & 5.644 \\
\hline $4 . \overline{0}$ & 102.2 & 2.423 & 43.65 & 5.672 \\
\hline 5.0 & 102.0 & $2.4 \pm 7$ & 43.34 & 5.713 \\
\hline 5.5 & & & 43.26 & 5.724 \\
\hline 6.0 & 101.5 & 2.439 & 43.21 & 5.730 \\
\hline 6.0 & 101.2 & 2.447 & & \\
\hline 7.0 & 101.1 & 2.449 & & \\
\hline 7.5 & 100.8 & 2.456 & & \\
\hline 8.0 & 100.7 & 2.459 & & \\
\hline 8.5 & 100.4 & 2.466 & & \\
\hline 9.5 & 100.0 & 2.476 & & \\
\hline 10.0 & 99.72 & 2.483 & & \\
\hline 10.5 & 99.50 & 2.488 & & \\
\hline 11.0 & 99.16 & 2.497 & & \\
\hline 11.5 & 98.86 & 2.505 & & \\
\hline 21.0 & & & 43.21 & 5.730 \\
\hline 25.5 & 96.78 & 2.558 & & \\
\hline 26.5 & 96.78 & 2.558 & & \\
\hline
\end{tabular}

乾燥器中で長く放琵せる試料の 0.01 モル溶液ね 110 分で平衡に洋 し抵挄 $217 . t$, 比傅導度は $1.139 \times$ $10^{3}$ で著しく小，又渮性曹達を多 量に州へて再結晶せるb口000.02 モル溶液は7衡に達したとを抵抗 北傅導度林 $2.681 \times 10^{-3}$ で遥加に 大でする。

b) $\mathrm{C}_{5} \mathrm{H}_{6} \mathrm{ON}_{3} \mathrm{SCu} \cdot \mathrm{NaOH} \sigma$ $0.1299 \mathrm{~g}$ 即ち 0.005 モルを少量の水 に溶し直に4-イミノぇ-メチルチオ バルビッル酸の $0.05238 \mathrm{~g}$ 師ち $\frac{2}{3} \times 0.005$ モと湯と○混合物中 飞力n $100 \mathrm{cc}$ 足容懪儿入れ啠く 振盜すれば酸は2完全に溶解し淡黄 線色口溶液乞なる.18 $100 \mathrm{cc}$ Kなし比俱導噔を测定する。 抵扰 718.9 , 比葆领度 $3.441 \times 10^{-5}$

30 分後专同值を示亦.

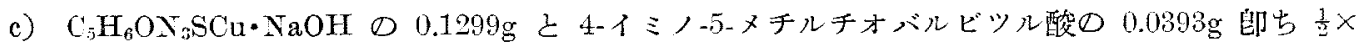

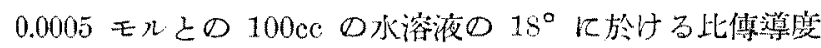

$\begin{array}{lcccc}\text { 時間 (分) } & 40 & 50 & 60 & 70 \\ \text { 抵 抗 } & 604.4 & 603.2 & 603.0 & 603.0 \\ \text { 比傅遒度 } & 4.097 \times 10^{-4} & 4.105 \times 10^{-4} & 4.106 \times 10^{-4} & 4.106 \times 10^{-4}\end{array}$

d) $\mathrm{C}_{5} \mathrm{H}_{6} \mathrm{ON}_{3} \mathrm{SCu} \cdot \mathrm{NaOH} の 0.0825 \mathrm{~g}$ 即与 $\frac{1}{4} \times 0.0005$ モルと4-イミノー5ーメチルオバルビツル酸ナ

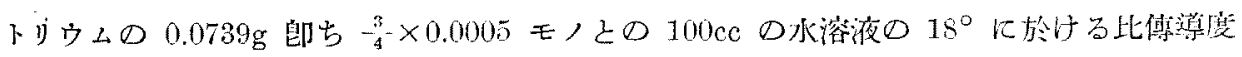

\begin{tabular}{|c|c|c|c|c|}
\hline 洔間 (分) & 10 & 15 & 20 & 30 \\
\hline 抗 & 600.0 & 599.1 & 598.5 & 598.5 \\
\hline 傅導度 & $4.127 \times 10^{-4}$ & $4.133 \times 10^{-4}$ & $4.137 \times 10^{-4}$ & $1.137 \times 10^{-1}$ \\
\hline
\end{tabular}


6. 水點降下法による $\mathrm{C}_{5} \mathrm{H}_{6} \mathrm{ON}_{3} \mathrm{SCu} \cdot \mathrm{NaOH}$ の分子量測定 $\mathrm{C}_{5} \mathrm{H}_{6} \mathrm{ON}_{3} \mathrm{SCu} \cdot \mathrm{NaOH}$ は䇥だ吸濕性で

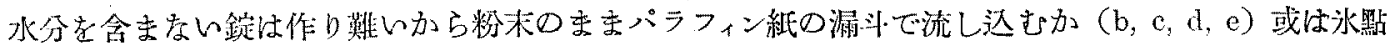
を测定した水を用ひ試料の一定量を定容湦に大れその水で溶解（a）して溶液の水點降下を定めを.

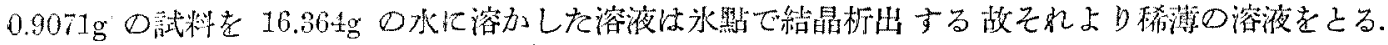

$1000 \mathrm{~g}$ の水に

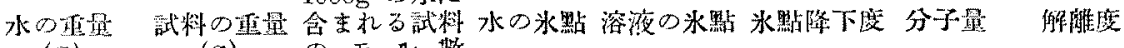
$(\mathrm{g}) \quad(\mathrm{g}) \quad \Phi \mp \pi$ 数

\begin{tabular}{|c|c|c|c|c|c|c|c|}
\hline (a) & 24.913 & 0.1296 & 0.0200 & 3.743 & $\begin{array}{l}3.682 \\
3.682\end{array}$ & 0.061 & 158 \\
\hline (b) & 15.033 & 0.1514 & 0.0388 & 3.760 & $\begin{array}{l}3.640 \\
3.640\end{array}$ & 0.120 & 155 \\
\hline (c) & 15.750 & 0.2029 & 0.0496 & 3.760 & $\begin{array}{l}3.620 \\
3.620\end{array}$ & 0.140 & 170 \\
\hline (d) & 15.750 & 0.2544 & 0.0622 & 3.750 & $\begin{array}{l}3.593 \\
3.593\end{array}$ & 0.167 & 179 \\
\hline (e) & 16.315 & $0 . \tilde{0} 314$ & 0.1254 & 3.760 & $\begin{array}{l}3.480 \\
3.480\end{array}$ & 0.280 & 215 \\
\hline
\end{tabular}

$1000 \mathrm{~g}$ ○水に含まれる試料のモル數又は水點降下度を横軸にとり分子量を縱軸にとれば分子量は（e）

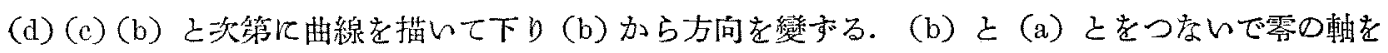

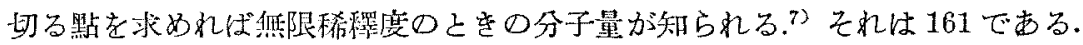

\section{摘 要}

1. 4-イミノ-5ーメチルチオバルビツル酸ナトリウムの溶液に醋酸銅を作用させると一價銅の化合物

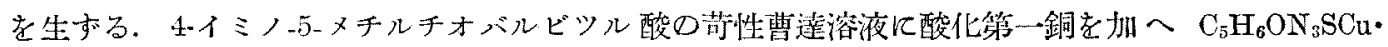
$\mathrm{NaOH}$ 得た。

2. $\mathrm{C}_{5} \mathrm{H}_{6} \mathrm{ON} 3 \mathrm{SCu} \cdot \mathrm{NaOH}$ 溶液を蓝酸で酸性にして $\mathrm{C}_{5} \mathrm{H}_{6} \mathrm{ON}_{3} \mathrm{SCu} \cdot \mathrm{C}_{5} \mathrm{H}_{7} \mathrm{ON}_{3} \mathrm{~S} \cdot \mathrm{HCl}$ を得た.

3. $\mathrm{C}_{5} \mathrm{H}_{6} \mathrm{ON}_{5} \mathrm{SCu} \cdot \mathrm{NiOH}$ は酸で中和する際 $\left(\mathrm{C}_{5} \mathrm{H}_{6} \mathrm{ON}_{3} \mathrm{SCu}\right)_{2} \mathrm{CuOH}$ と 4-イミノー5ーメチルチオバル

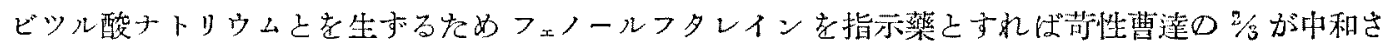
れる。

4. $\mathrm{C}_{5} \mathrm{H}_{6} \mathrm{ON}_{3} \mathrm{SCu} \cdot \mathrm{NaOH}$ の水溶液は解離して $\left(\mathrm{C}_{5} \mathrm{H}_{6} \mathrm{ON}_{5} \mathrm{SCu}\right)_{2} \mathrm{NaOH}, \mathrm{C}_{5} \mathrm{H}_{6} \mathrm{ON}_{3} \mathrm{SCu} \cdot \mathrm{OH}^{\prime}, \mathrm{Na}^{*}$ 及 ぜ $\mathrm{OH}^{\prime}$ を生じ平衡に達するまで相虽の時間を要することが比傳導度测定によつて知られた。

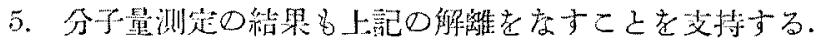

(旅順工科大學瑍科)

7) H. Biltz, tr. by Jones, King: "Practical Jethods for Determining Molecular Weights," 120. 